Gefässchirurgie 2016 · 21:64-65 DOI 10.1007/s00772-015-0107-5

Online publiziert: 21. Dezember 2015

๑) Springer-Verlag Berlin Heidelberg 2015

CrossMark
E. Kleinspehn ${ }^{1}$ - T. Kühme ${ }^{1}$ - G. Atlihan ${ }^{1}$ · C. Gebhardt ${ }^{2}$ - E.S. Debus ${ }^{1}$

${ }^{1}$ Klinik und Poliklinik für Gefäßmedizin, Gefäßchirurgie - Endovaskuläre Therapie -

Angiologie, Deutsches Aortenzentrum Hamburg, Universitäres Herzzentrum,

Universitätsklinikum Hamburg-Eppendorf, Hamburg, Deutschland

${ }^{2}$ Abt. für Gefäßchirurgie, Klinik Fleetinsel, Hamburg, Deutschland

\section{Erratum zu: Offen-operative Therapiemöglichkeiten beim postthrombotischen Syndrom (PTS)}

\section{Erratum zu:}

Gefässchirurgie 2015 20:498-502

DOI:10.1007/s00772-015-0089-3

In diesem Beitrag wurden leider die Legenden der $\bullet$ Abb. 5 bis 7 vertauscht. Wir bitten die folgende korrekte $\mathrm{Zu}$ ordnung zu beachten und den Fehler zu entschuldigen.

Die Redaktion

\section{Korrespondenzadresse}

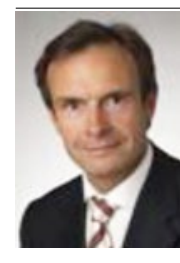

Prof. Dr. E.S. Debus

Klinik und Poliklinik für

Gefäßmedizin, Gefäßchirurgie -

Endovaskuläre Therapie -

Angiologie, Deutsches

Aortenzentrum Hamburg,

Universitäres Herzzentrum,

Universitätsklinikum

Hamburg-Eppendorf

Martinistr. 52, 20246 Hamburg

debus@uke.de 


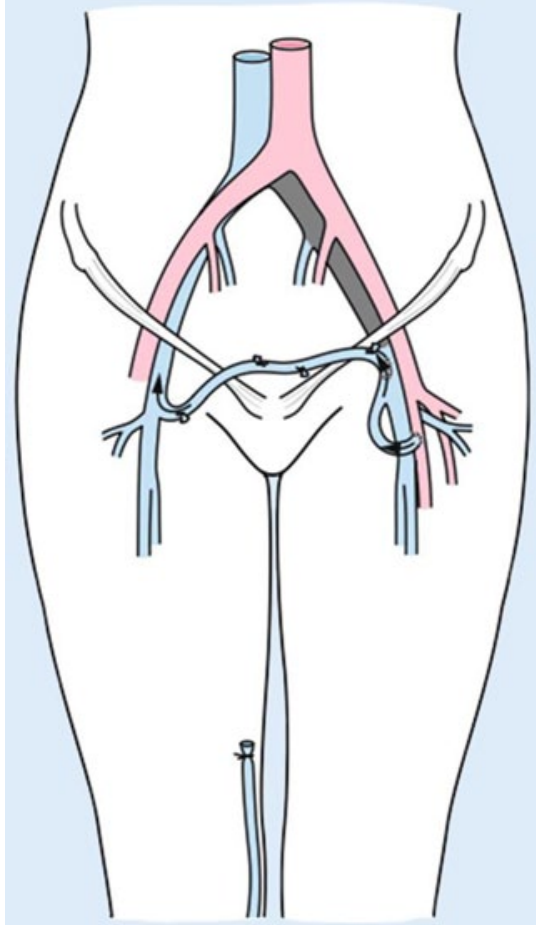

Abb. $5 \Delta$ Femorofemoraler Venenbypass mit V. saphena magna bei chronischem Beckenvenenverschluss links („Palma-Operation“) [11]

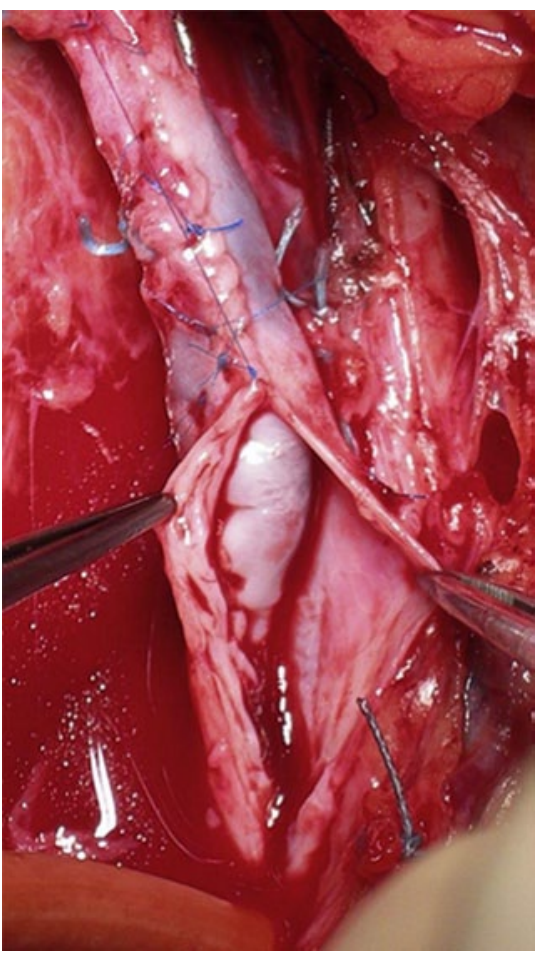

Abb. $6 \Delta$ Operativ geschaffene, suffiziente Neoklappe. Kein Reflux distal der Neoklappe sichtbar

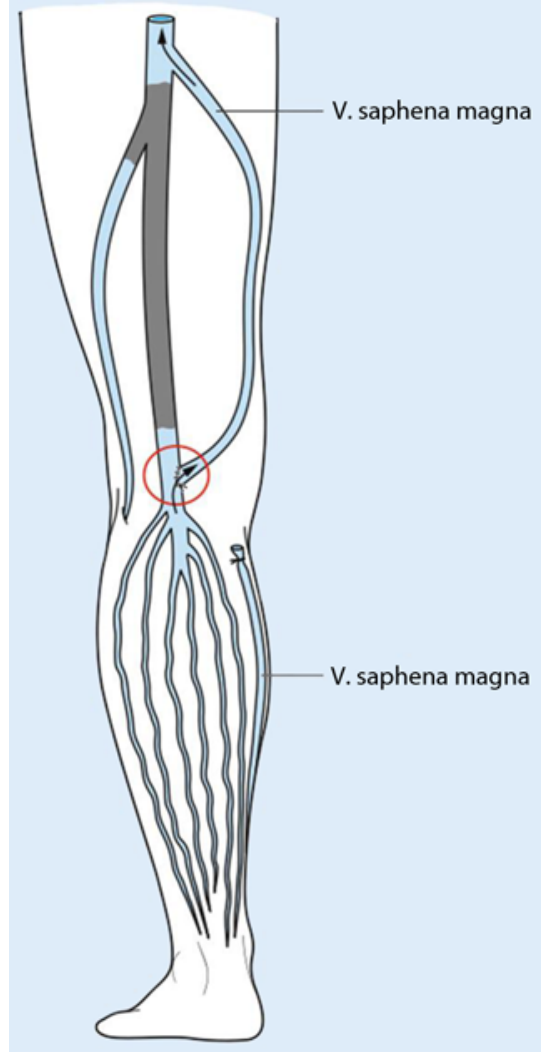

Abb. 7 \ Saphenopoplitealer Bypass links („May-Husni-Operation“) [11] 